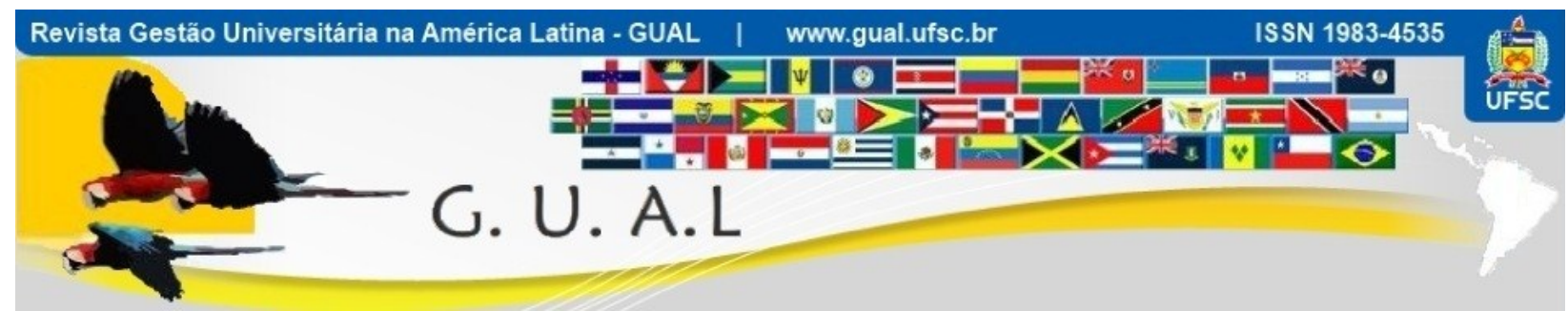

DOI: http://dx.doi.org/10.5007/1983-4535.2012v5n3p46

\title{
IMPLANTAÇÃO DO PROCESSO DE GESTÃO: ESTUDO DE CASO EM UMA FUNDAÇÃO DE APOIO À UNIVERSIDADE PÚBLICA
}

\author{
IMPLEMENTATION PROCESS MANAGEMENT: A CASE STUDY ON A \\ FOUNDATION TO SUPPORT PUBLIC UNIVERSITY
}

Cristiane Gularte Quintana, Mestre Universidade de Caxias do Sul - UCS cristianequintana@hotmail.com

Paula Patricia Ganzer, Mestre Universidade de Caxias do Sul - UCS paula.ganzer@bol.com.br

Eliana Andrea Severo, Mestre Universidade de Caxias do Sul - UCS elianasevero2@hotmail.com

Pelayo Munhoz Olea, Doutor Universidade de Caxias do Sul - UCS pelayo.olea@gmail.com

Eric Henri Dorion, Doutor Universidade de Caxias do Sul - UCS echdorion@gmail.com

Recebido em 05/outubro/2012

Aprovado em 28/novembro/2012

Sistema de Avaliação: Double Blind Review

Esta obra está sob uma Licença Creative Commons Atribuição-Uso. 


\title{
RESUMO
}

O terceiro setor vem se consolidando na economia do País, por isso torna-se essencial que o Estado, bem como a sociedade tenha consciência e controle de como são administrados os recursos públicos. O objetivo desta pesquisa foi identificar quais são as mudanças ocorridas no processo de gestão, a partir de uma nova diretoria em uma Fundação de Apoio à Universidade Pública. A metodologia caracteriza-se pela abordagem qualitativa; descritiva, por delinear quais são as ações de gestão adotadas; pesquisa documental, por utilizar como instrumento o Estatuto da Fundação; e quanto aos procedimentos, trata-se de um estudo de caso. Os dados da pesquisa foram obtidos através de entrevista com o Diretor Executivo da Fundação. Como resultados obtidos destacam-se as ações administrativas, utilizadas pela nova diretoria, entre elas: redefinir as ações relacionadas a recursos humanos; criar um manual de procedimentos internos; e planejar as ações da Fundação. Concluiu-se que o uso do processo de gestão tornou-se um diferencial na atuação da Fundação, pois ofereceu condições para a Direção tratar das questões estratégicas, sem a necessidade de estar envolvida com as questões operacionais, e que as ações de gestão podem ser aplicadas em organizações de terceiro setor.

Palavras-chave: Gestão. Terceiro setor. Fundações de apoio.

\begin{abstract}
The third sector has been consolidating in the country's economy, so it is essential that the state and society to become aware and control how public resources are managed. The objective of this research was to identify what are the changes in the management process, from a new board in a Foundation to Support Public University. The methodology is characterized by qualitative approach, descriptive, by outlining what are the management actions taken; documentary research, as a tool used by the Foundation Statute, and as to the procedures, it is a case study. Survey data were obtained through interviews with the Executive Director of the Foundation. As results stand out administrative actions, used by the new board, including: reset actions related to human resources to create a manual of internal procedures, and planning the actions of the Foundation. It was concluded that the use of process management has become a differentiator in the work of the Foundation, for making possible to treat the direction of the strategic issues without the need to be involved in operational matters, and that management actions can be applied in third sector organizations.
\end{abstract}

Keywords: Management. Third sector. Foundations of support. 


\section{INTRODUÇÃO}

O terceiro setor vem se consolidando como um importante setor na economia do País, por isso, torna-se essencial que o Estado, bem como a sociedade em geral tenha consciência e controle a respeito de como são administrados os recursos públicos repassados às entidades incluídas neste setor da economia.

Para Paes (2001), no terceiro setor, configuram as entidades de interesse social sem fins lucrativos, como associações, sociedades e as fundações com gestão própria. O objeto de estudo desse trabalho foi uma fundação. Conforme Szazi (2006, p. 37) define-se fundação como "um patrimônio destinado a servir, sem intuito de lucro, a uma causa de interesse público determinada, que adquire personificação jurídica por iniciativa de seu instituidor".

As organizações do terceiro setor são movidas pelo desejo de melhoria do mundo e as pessoas que nelas trabalham e administram de forma voluntária, acreditam na criação de um mundo justo, compreensivo, esclarecido e saudável. Entretanto, a administração é importante para o êxito dessas organizações (HUNDSON, 2002).

De acordo com Willians (2010, p. 3) "administração é a realização de um trabalho por meio de outras pessoas", e que os gestores necessitam se preocupar com a eficiência e eficácia nesse processo, por meio de quatro funções administrativas: o planejamento, que é a determinação das metas; a organização, que significa definir onde as decisões serão tomadas, quem cumprirá e quem trabalhará para quem; a liderança, que abrange inspirar e motivar os funcionários para que se comprometam para alcançar as metas organizacionais; e a última função é a de controle, que incide no acompanhamento das melhorias em direção ao cumprimento das metas e na adoção de medidas corretivas. Para a gestão de projetos, as fundações de apoio recebem financiamento de instituições públicas e privadas o que torna relevante o domínio e físcalização destas entidades pelo Estado e sociedade.

Com base nos valores movidos pela ação social, às organizações do terceiro setor não se dedicavam em administrar, porém com o crescimento e o aumento dos desafios e problemas que demonstravam ameaçar a sobrevivência das mesmas, iniciou-se um processo de discussão de gestão (SOARES, 2008). A partir da década de 90 as organizações do terceiro setor perceberam que a administração era importante para sua existência, por isso viram-se obrigadas a repensar a sua missão, a forma como atuavam e a maneira como funcionavam a fim de enfrentar os desafios de gestão (HUDSON, 1999; TENÓRIO, 2004). 
Diante do exposto, o problema de pesquisa fundamentou-se na seguinte questão: Quais são as mudanças ocorridas no processo de gestão, a partir de uma nova diretoria em uma organização do terceiro setor? Logo, o objetivo da pesquisa foi identificar quais são as mudanças ocorridas no processo de gestão, a partir de uma nova diretoria em uma Fundação de Apoio à Universidade Pública.

Esta pesquisa foi realizada em uma Fundação de Apoio à Instituição de Ensino Superior, localizada no Estado do Rio Grande do Sul, sendo esta uma entidade de direito privado, sem fins lucrativos, com personalidade jurídica própria. De acordo com seu estatuto, a fundação é composta por um conselho deliberativo, uma diretoria executiva, um conselho fiscal e um corpo de funcionários, e que apresenta como objetivos gerais:

- I - Apoiar a universidade na consecução de seus objetivos, no âmbito do ensino, da pesquisa e da extensão;

- II - Promover o desenvolvimento científico e tecnológico, as atividades artísticas e culturais, a preservação ambiental e as relações institucionais entre a universidade, a comunidade universitária e a sociedade.

O estudo se justificou pela relevância que as práticas de gestão possuem nas associações, sociedades e fundações para melhor apresentar e conduzir as informações de interesse da sociedade, pois para Kohama (2000, p. 44) “as fundações não dispensam a fiscalização institucional do Ministério Público, que velará pela observância de seus Estatutos e denunciará as irregularidades ao órgão estatal a que estiver vinculada”.

\section{REFERENCIAL TEÓRICO}

\subsection{GESTÃO}

A teoria das organizações é composta por várias peças, como um mosaico, esse sistema está em constante movimento, surgem novos elementos que alteram a sua compreensão, a busca do entendimento é contínua para tentar encaixar as diversas peças. Portanto, o conhecimento e a compreensão serão desafiados em outros momentos, onde acontecerá o conhecimento humano, sendo este, dinâmico e constante, que permite enxergar novas realidades e conceitos em nível de compreensão cada vez maior (MOTTA e VASCONCELOS, 2008).

$\mathrm{Na}$ linha do tempo, a abordagem clássica foi o primeiro esforço da administração para desenvolver uma teoria formal para as modernas organizações industriais, originadas da 


\section{IMPLANTAÇÃO DO PROCESSO DE GESTÃO: ESTUDO DE CASO EM UMA FUNDAÇÃO DE \\ APOIO À UNIVERSIDADE PÚBLICA \\ DOI: http://dx.doi.org/10.5007/1983-4535.2012v5n3p46}

Revolução Industrial. A abordagem humanística enfatizou o elemento humano e o seu comportamento coletivo nas organizações. Quanto à abordagem quantitativa que surgiu na Segunda Guerra Mundial, provocou mudanças na administração, os administradores necessitavam de melhores ferramentas para a tomada de decisão, o foco era quantitativo nas práticas e conceitos gerenciais. Já a abordagem moderna foi contemplada com a teoria dos sistemas e das contingências, integrando as três abordagens anteriores. A abordagem contemporânea foi uma síntese das abordagens anteriores com outras mais recentes, com o objetivo de construir melhorias na administração (SILVA, 2005).

Segundo Koontz (1966) a administração é uma arte que pode ser aprimorada pela compreensão e por meio da utilização de princípios, ou seja, a administração é a arte de realizar acontecimentos por meios de pessoas em grupos organizados, de modo que as pessoas possam agir individualmente, porém cooperando para conseguir objetivos grupais, afastando os obstáculos, esta é a arte de otimizar a eficiência para atingir eficazmente os objetivos. Alguns critérios da teoria administrativa precisam ser adotados: a teoria terá que lidar com a área do conhecimento e averiguação que seja tratável, pois não se realizaram grandes avanços no conhecimento enquanto o homem limitou-se a contemplar o Universo como um todo; a teoria deverá ser útil para o aperfeiçoamento da prática administrativa, sem deixar de atender à pessoa do administrador e às suas tarefas; a teoria não deve perder-se em questões de terminologia; a teoria precisa fornecer uma diretriz e conferir a eficácia para a pesquisa e para o ensino da Administração; e por fim, a teoria administrativa necessita reconhecer que faz parte de um universo maior de conhecimento e de teoria.

$\mathrm{Na}$ teoria da administração científica a ênfase foi nas tarefas dos empregados; sobre a teoria administrativa destacou-se a ênfase nas estruturas da organização; as regras, a divisão do trabalho, a hierarquia e a estrutura da autoridade formaram a teoria da burocracia; na teoria da transição mostrou como a organização formal e a parte das relações humanas poderiam ser interligadas, onde contribuiu para a formação da teoria das relações humanas que foi voltada para as pessoas que fazem parte da organização; já a escola comportamentalista refletiu o estudo dos indivíduos e grupos nas organizações (SILVA, 2005).

Ainda dando continuidade a ênfase de cada teoria, a teoria estruturalista contribuiu para o estudo das organizações num sentido mais amplo, levando em consideração todos os fatos; a pesquisa operacional explorou a situação, por meio de modelos e práticas matemáticas; já os sistemas de informações gerenciais representaram o desenvolvimento e uso de sistemas de 


\section{IMPLANTAÇÃO DO PROCESSO DE GESTÃO: ESTUDO DE CASO EM UMA FUNDAÇÃO DE \\ APOIO À UNIVERSIDADE PÚBLICA \\ DOI: http://dx.doi.org/10.5007/1983-4535.2012v5n3p46}

informações eficazes, que contribuiu para a teoria dos sistemas gerando a visão do todo, por meio de uma concepção holística; a teoria das contingências procurou entender as relações dentro e dentre os subsistemas; logo o desenvolvimento organizacional ajudou os administradores a alcançar um grau de síntese da organização; entretanto a administração por objetivo relacionou as metas da organização com o desempenho e desenvolvimento individual em todos os níveis administrativos; o termo qualidade na administração foi considerado, a característica de um produto ou serviço que propicia a habilidade de satisfação das necessidades dos clientes; a definição de excelência operacional partiu de um conjunto de características que resultam na excelência das organizações; o significado dos projetos foi definir novas formas da estrutura organizacional; e para concluir o quadro das escolas e suas respectivas teorias, os processos da administração foram definidos, como uma sequência de atividades arranjadas num procedimento (SILVA, 2005).

Segundo Lacombe e Heilborn (2008) as tendências da administração estão sendo unificadas às práticas administrativas, fundindo-se com outras e em alguns casos, podem desaparecer como modismo. Para o autor as tendências atuais da Administração são: Qualidade Total e Benchmarking, Aperfeiçoamento dos Processos, Gestão do Conhecimento, e a Nova Administração. Neste contexto, destaca-se a nova administração, como base teórica para entendimento das práticas realizadas nas organizações do terceiro setor. A nova administração compõe-se pelas novas formas de vínculos entre trabalhadores e organizações, as organizações virtuais, a criatividade e inovação, a prioridade do cliente e a importância dos recursos humanos.

Nas novas formas de vínculos entre trabalhadores e organização, destacam-se a terceirização, que é transferir para outras empresas, mediante contrato, as atividades não essenciais da empresa; o teletrabalho, permitindo que o trabalho possa ser feito em casa, ou em escritórios próximos da residência; e as jornadas atípicas, que classifica o horário de trabalho móvel. As organizações virtuais caracterizam-se como elos interorganizacionais, sem a necessidade de possuir uma localização. Entretanto a criatividade e inovação valorizam as formas de organização que proporcionam condições para a criatividade e a inovação; e sobre tudo, o aumento da competição trouxe para primeiro plano a importância e a prioridade que deve ser dada ao cliente, e por fim, como os recursos humanos são o recurso fundamental para a organização, a empresa deve estar à sua escuta se quiser iniciar o verdadeiro aprendizado de uma administração adaptada ao mundo atual (LACOME e HEILBORN, 2008). 


\section{IMPLANTAÇÃO DO PROCESSO DE GESTÃO: ESTUDO DE CASO EM UMA FUNDAÇÃO DE \\ APOIO À UNIVERSIDADE PÚBLICA \\ DOI: http://dx.doi.org/10.5007/1983-4535.2012v5n3p46}

O modelo de negócios contemporâneo exige uma integração da criatividade em todo o processo decisório, e que o negócio para ser bem sucedido necessita inovar, pois por meio da inovação, as ofertas de valor da empresa crescem interna e externamente. A criatividade é a mais notável capacidade de pensar de forma diferente, um novo modelo de negócios deve incorporar acriatividade em todos os níveis da organização e abraçar o processo criativo que leva a pensar diferente (DAVIS, 2010).

A respeito da importância dos recursos humanos nas organizações, Boudreau e Ziskin (2011) abordam que, o sucesso das relações humanas nas organizações eficazes, vão depender da fronteira do RH com diversas definições do seu papel. Os autores apontam seis grandes tendências: i) da liderança herói a liderança coletiva; ii) propriedade intelectual ágil e cocriatividade; iii) proposição de valor para o emprego e valor pessoal; iv) mesmice à segmentação; v) fadiga humana e a sustentabilidade; e, vi) persuasão para a educação. A organização do futuro vai ver todos os funcionários como líderes, e as pessoas vão ter responsabilidade e autoridade para agir ao invés de esperar uma ordem de cima. Hoje os desafios que afrontam uma organização são tão complexos que requerem um conjunto de competências. A promessa de um RH futuro pode estar em um futuro, em que não só os recursos humanos apresentam um excelente trabalho, mas também as organizações e seus constituintes tornam-se "mais inteligentes" sobre o emprego do capital humano como resultado.

As funções gerenciais fundamentais ao processo de administração são: planejamento, organização, direção e controle, e essas funções precisam ser entendidas como um ciclo que se repete dentro da organização estando relacionada com previsão, divisão do trabalho, execução e monitoramento. O campo de gestão é avaliado como um dos espaços centrais na obtenção do avanço das organizações do Terceiro Setor, o que exige um esforço no desenvolvimento de instrumentos e estruturas gerenciais apropriados para mensurar e monitorar processos, resultados e impactos em projetos realizados de modo que os objetivos sociais sejam obtidos (TEODÓSIO, 1999). Segundo Tenório (2004 p. 17) "gerenciar é orientar a dinâmica da organização. Para que uma atividade seja bem sucedida é preciso uma boa utilização dos recursos e o direcionamento desses recursos para atingir a finalidade proposta pelos membros da organização". 


\section{IMPLANTAÇÃO DO PROCESSO DE GESTÃO: ESTUDO DE CASO EM UMA FUNDAÇÃO DE \\ APOIO À UNIVERSIDADE PÚBLICA \\ DOI: http://dx.doi.org/10.5007/1983-4535.2012v5n3p46}

\subsection{TERCEIRO SETOR}

O terceiro setor consiste em organizações, no qual os objetivos são sociais, ao invés de econômicos, o setor engloba as instituições de caridade, religiosas, entidades voltadas às artes, comunitárias, sindicatos, associações profissionais e organizações voluntárias. O termo "terceiro setor" diferencia as organizações de "setor público" do "setor privado". As organizações do terceiro setor diferem das organizações do setor privado, pois não distribuem lucros a seus proprietários e não estão sujeitas a um controle direto político, como é o caso das organizações do setor público, por isso essas organizações possuem independência na determinação do próprio futuro (Hudson, 2002). Para Fernandes (2005) o terceiro setor é composto por organizações que não possuem fins lucrativos, sendo instituídas e mantidas pela participação espontânea em uma esfera não governamental, proporcionando continuidade às práticas habituais de caridade, filantropia no qual expandem o seu sentido para outros domínios devido à incorporação conceitual de cidadania e usa múltiplas manifestações na sociedade civil.

A administração do terceiro setor possui diferenças em relação ao primeiro e segundo setores, de acordo com os valores e crenças das pessoas, na administração associada aos relacionamentos com o público, demonstra fragilidade na conexão entre usuários e financiadores dos serviços. Neste contexto a administração do terceiro setor possui tarefas desafiadoras, sendo elas: a facilidade em obter objetivos imprecisos, difícil monitoramento de desempenho, estruturas administrativas complicadas, a presença dos voluntários, os valores sociais, diversos patrocinadores e a inexistência da procura pelo lucro (HUDSON, 1999).

O terceiro setor possui três faces, a primeira face é a ideia, como conceito ideal, atrai as pessoas para seu campo. Os valores do terceiro setor são múltiplos e inclui compaixão, desapego, sensibilidade com os desprovidos e compromisso ao direito de livre expressão. A segunda fase relaciona-se com o terceiro setor como realidade, que segue oculta e uma das razões são baseadas na experiência, ou seja, por falta de informações consistentes. A terceira fase denomina o terceiro setor como ideologia, onde se pensava que no terceiro setor havia incompetência, que somente auxiliava as classes necessitadas e que a doação privada e as ações voluntárias seriam as únicas fontes de apoio apropriadas ao terceiro setor (IOSCHPE, 2005).

De acordo com Tenório (2004) o terceiro setor possui o desafio de formar diálogo com setores governamental e empresarial, o que constitui a oportunidade da conquista de novos 
espaços por parte das ONGs, podendo beneficiar-se tomando iniciativas de ações de parcerias com estes setores. Segundo autor (p. 11) "as ONGs caracterizam-se por serem organizações sem fins lucrativos, autônomas, isto é, sem vínculo com o governo, voltadas para o atendimento das necessidades de organizações de base popular, complementando a ação do Estado".

Desde o final da II Guerra Mundial, em que o mundo sofreu transformações em sua história, houve o aumento da pobreza, violência doenças, poluição ambiental juntamente com desordens sociais, políticas e religiosas, frente a estes problemas, as ONGs que possuíam estilo assistencialista em grupos religiosos, passaram a seguir como estratégia a ação localizada de pequenas dimensões. Na década de 70 a estratégia caracterizou-se na América Latina, com ações voltadas para uma política social de desenvolvimento comunitário, desde atividades de autoajuda até educação e saúde. Na década de 80 as ONGs passaram a enfrentar desafios perante a sua forma de gestão, a situação assumiu algumas características, entre elas, o aumento dos índices de inflação, a vigência de governos democráticos, a fundação de políticas neoliberais de desenvolvimento, o que agrava a pobreza, o crescimento do setor informal econômico e o descrédito do Banco Mundial e de instituições internacionais em relação aos recursos alocados em programas de desenvolvimento social, referente ao destino dado aos recursos. No entanto na década de 90, as ONGs viram-se diante dos desafios como: migrar do micro para o macro; sair do privado para o público, passar da resistência para a proposta (TENÓRIO, 2004).

No entanto fala-se das organizações da sociedade civil (OSCs) como um conjunto que se difere do estado e do mercado, portanto a sociedade civil destacou um espaço próprio, não governamental e de participação em causas coletivas. Na sociedade civil, os indivíduos e instituições particulares poderiam praticar a cidadania autônoma e diretamente, pois estar nesta sociedade insinuaria simbolicamente um sentido de domínio do cidadão (IOSCHPE, 2005).

Nos últimos 15 anos, o conceito de empresa social tem levantado um interesse crescente em várias regiões do mundo, primeiro na Europa e nos Estados Unidos e mais recentemente em outras regiões como o Leste da Ásia (Japão e na Coréia do Sul), e na América Latina. Em especial na Europa, o conceito de empresa social fez sua primeira aparição por volta do ano1990, com a identificação de dinâmica empresarial, no coração do terceiro setor, que surgiu principalmente em resposta às necessidades sociais que 
haviam sido mal atendidas pelos serviços públicos, ou pelas empresas privadas. É fundamental notar que, em contraste com a tradição dos EUA, a maioria dos estudiosos na tradição européia olha $o$ terceiro setor como uma reunião de cooperativas, associações, mutualidades e cada vez mais fundações, em outras palavras, organizações sem fins lucrativos (DEFOURNY e NYSSENS, 2010).

O objetivo principal de organizações sem fins lucrativos na Alemanha, não é a barganha econômica, mas sim oferecer serviços a vários clientes e promover o bem público. O Estado está delegando a prestação de serviços a estas organizações, atuando como comprador. Por sua vez, as organizações recebem proteção pública para realizar sua missão. Consequentemente, a noção de corporativismo no campo dos serviços sociais, concentra-se principalmente com a colaboração entre o Estado e o terceiro setor, o que levou a um comum planejamento e o reconhecimento das organizações sem fins lucrativos (DAVIES, 2008).

Segundo Maximiano (2007, p. 6) a definição dos tipos de organizações é a seguinte:

Governo: compreende as organizações do serviço público, que administram o Estado e prestam serviços aos cidadãos. Empresa: é uma organização de negócios, que tem por objetivos de vender produtos e serviços e obter lucro. Terceiro setor: o chamado terceiro setor compreende as organizações de utilidade pública, que têm origem na sociedade e não no governo.

De acordo com Drucker (1976, p. 216) “As entidades que não constituem empresas: o governo, as forças armadas, as universidades, os hospitais, começaram a aplicar a si mesmos os conceitos e métodos da administração de empresas. E isso é realmente novo. É espantoso". Com isto, começou-se a observar a necessidade do uso de práticas de gestão em entidades sem fins lucrativos.

Segundo Resende (2006, p. 43) “a Fundação de natureza jurídica de direito privado, tem seu nascimento com a inscrição de seu estatuto e da escritura de instituição, no registro civil das pessoas jurídicas, após aprovação do Ministério Público”.

Conforme o art. $1^{\text {o }}$ da lei 8958/94 as Fundações de Apoio são:

As Instituições Federais de Ensino Superior-IFES, bem como as Instituições Científicas e Tecnológicas - ICTs, sobre as quais dispõe a Lei $\mathrm{n}^{\mathrm{0}}$ 10.973 , de 2 de dezembro de 2004, poderão realizar convênios e contratos, nos termos do inciso XIII do art. 24 da Lei no 8.666, de 21 de junho de 1993, por prazo determinado, com fundações instituídas com a finalidade de dar apoio a projetos de ensino, pesquisa e extensão e de desenvolvimento institucional, científico e tecnológico, inclusive na gestão administrativa e financeira estritamente necessária à execução desses projetos. 
De acordo com o estatuto da fundação de apoio, objeto de estudo dessa pesquisa, os objetivos específicos são: celebrar convênios, contratos, acordos, ajustes, estabelecer ou intervir em relações entre a universidade e instituições de ensino, pesquisa, extensão, fomento ou financiamento; integrar organismos multilaterais, consórcios e condomínios de âmbito local, regional, nacional ou internacional; divulgar e fomentar os programas, planos, projetos e atividades de pesquisa e extensão da universidade, captar recursos, gerenciar recursos externos, elaborar prestação de contas e subsidiar relatórios; divulgar e fomentar a prestação de serviços técnico-científicos da universidade.

Segue ainda no estatuto, promover cursos, seminários, congressos e outros eventos de capacitação, informação e difusão de conhecimentos técnico-científicos; instituir bolsas de estudo, de pesquisa ou de extensão para o corpo docente, técnico-administrativo e marítimo e discente da universidade; instituir programas de incremento nas condições de trabalho, capacitação de pessoal, infraestrutura e modernização de equipamentos, visando aos interesses da universidade; promover a divulgação e aplicação do conhecimento científico, tecnológico e artístico, através da consolidação, registro e gerenciamento de direitos de propriedade intelectual; e contribuir para a manutenção dos objetivos da universidade, desenvolvendo atividades e realizando receitas a partir de excedentes de pesquisa ou de extensão e da promoção institucional.

De acordo com Tristão (2000, p. 6), em relação à finalidade das fundações de apoio salienta que:

É oportuno alertar que não devem ser permitidos desvios de finalidade no apoio fundacional, com utilização de parte de seus recursos para suplementação salarial de professores e servidores técnico-administrativos sem a contraprestação de serviços específicos em projetos ou atividades das fundações.

Conforme o estatuto da fundação de apoio pesquisada, os recursos são provenientes de convênios, acordos, auxílios, doações ou dotações; pelas remunerações recebidas por serviços prestados; pelas rendas próprias dos bens que possua ou administre; pelas rendas destinadas por terceiros a seu favor; pelas rendas dos títulos, ações ou papéis financeiros de sua propriedade; pelos juros de capital e outras receitas da mesma natureza. Para Branco (1997, p. 2) relata que: "as entidades do terceiro setor são financiadas tanto por cessões, doações e contribuições privadas como por subvenções governamentais e frequentemente são contempladas com incentivos fiscais em função do interesse público de sua ação". 


\section{IMPLANTAÇÃO DO PROCESSO DE GESTÃO: ESTUDO DE CASO EM UMA FUNDAÇÃO DE \\ APOIO À UNIVERSIDADE PÚBLICA \\ DOI: http://dx.doi.org/10.5007/1983-4535.2012v5n3p46}

A necessidade de abordar o financiamento do terceiro setor é de fato uma questão importante. Diversificar os fluxos de financiamento, para além de bolsas tradicionais, contribuições e doações que forneceram o financiamento no passado, assume múltiplas formas em todo o terceiro setor. Estas estratégias podem envolver pagamento por serviço de entrega, ambos no setor público e privado. Na Grã-Bretanha, por exemplo, grande parte do esforço para a diversificação de receita veio a partir 1980, sob o governo conservador de Margaret Thatcher. Em muitos países, os governos não desenvolveram instrumentos de financiamento adequados, de modo que, mesmo quando procura-se promover o investimento e inovação social, estes são limitados em um modo de aquisição de serviços, devido a um excesso de dependência de contratos. As organizações sem fins lucrativos, como as empresas sociais, os voluntários, a comunidade e as organizações de caridade não são apenas uma parte integrante da prestação de saúde, educação, social, e outros serviços na maioria dos países desenvolvidos, mas também contribuintes para uma democracia saudável e uma economia forte (PHILLIPS e HEBB, 2010).

$\mathrm{Na}$ metade da década de 70 , a administração era vista como uma parte cultural do mundo dos negócios e não parecia servir para organizações orientadas por valores, sendo assim a administração não era uma palavra utilizada pelos indivíduos, quando tratava se das organizações do terceiro setor. Atualmente a administração está adaptando-se para organizações orientadas por valores e a sua linguagem e conceitos começam a surgir pelas pessoas tão fervorosamente quanto os discursos sobre a causa. O terceiro setor necessita de teorias de administração próprias, adotadas e adaptadas para a adequação de suas necessidades, que são diferentes de organizações públicas e privadas (HUNDSON, 2002).

\section{METODOLOGIA}

Este estudo mostra como o processo de gestão é aplicado por organizações do terceiro setor. Neste caso, um estudo sobre uma Fundação de Apoio a Universidade Pública.

Quanto à abordagem do problema, o estudo utilizou uma abordagem qualitativa para analisar a implantação do processo de gestão na fundação de apoio pesquisada, pois segundo Godoy (1995, p. 58) "não procura enumerar e/ou medir os eventos estudados, nem emprega instrumental estatístico", partindo de focos de interesses amplos, que vão se definindo no transcorrer do estudo. 


\section{IMPLANTAÇÃO DO PROCESSO DE GESTÃO: ESTUDO DE CASO EM UMA FUNDAÇÃO DE \\ APOIO À UNIVERSIDADE PÚBLICA \\ DOI: http://dx.doi.org/10.5007/1983-4535.2012v5n3p46}

Os dados da pesquisa foram obtidos através de uma entrevista semi estruturada, que conforme Martins e Theóphilo $(2009$, p. 88) “trata-se de uma técnica de pesquisa para coleta de informações, dados e evidências cujo objetivo básico é entender e compreender o significado que entrevistados atribuem a questões e situações, em contextos que não foram estruturados anteriormente".

Neste caso, foi entrevistado o diretor executivo da Fundação de Apoio, por meio da aplicação de um questionário.

Quanto aos objetivos, classifica-se como uma pesquisa descritiva, pois conforme Cervo e Bervian (2002, p. 66), a pesquisa descritiva "procura descobrir, com a precisão possível, a frequência com que um fenômeno ocorre, sua relação e conexão com outros, sua natureza e características". Nesse trabalho a intenção foi descrever qual o processo de gestão aplicado pela nova diretoria.

Como instrumento auxiliar para a análise dos dados, foi utilizado o estatuto da fundação, por isso, também pode se caracterizar o estudo como uma pesquisa documental, pois conforme Martins e Theóphilo (2009, p. 55), a pesquisa documental é "característica dos estudos que utilizam documentos como fonte de dados, informações e evidências". Nesse caso, o estatuto serve para evidenciar, as informações obtidas na base teórica.

A estratégia de pesquisa adotada quanto aos procedimentos foi o estudo de caso, conforme Yin $(2005$, p. 28) "foram utilizadas questões do tipo "como" e "por que" sobre um conjunto contemporâneo de acontecimentos, sobre o qual o pesquisador tem pouco ou nenhum controle". O resultado é denominado como estudo de caso, pois envolveu a avaliação de diferentes unidades da Fundação de Apoio pesquisada.

\section{ANÁLISE DOS RESULTADOS}

A Fundação de Apoio a Universidade Pública, alvo deste estudo, é gerida por uma diretoria composta pelo Diretor Executivo, o Diretor Secretário e o Diretor Tesoureiro, com um mandato de dois anos prorrogável por igual período. Os diretores são servidores públicos federais designados pelo Conselho Superior da Universidade apoiada, para atuarem na Fundação, definindo as estratégias e rumos da entidade. Assim, todo o processo de gestão é realizado por essa diretoria, principalmente, na pessoa do Diretor Executivo, que por força estatutária, é o representante legal e responsável pela condução da Fundação. 


\section{IMPLANTAÇÃO DO PROCESSO DE GESTÃO: ESTUDO DE CASO EM UMA FUNDAÇÃO DE \\ APOIO À UNIVERSIDADE PÚBLICA \\ DOI: http://dx.doi.org/10.5007/1983-4535.2012v5n3p46}

Neste sentido, a entrevista foi realizada com o Diretor Executivo procurando conhecer como são desenvolvidos os atos de gestão. A atual diretoria assumiu em janeiro de 2009, e já se encontra em seu segundo mandato, que tem vigência até dezembro de 2012. Quando o atual diretor assumiu, não existia a função de administrador entre os funcionários da Fundação, assim, toda a demanda operacional da entidade relacionada às decisões administrativas eram centralizadas no Diretor Executivo, e considerando, que por determinação legal, o servidor que desempenha essa função, não pode se desligar totalmente, da sua função normal e como servidor público, tornava-se complexo o processo de gestão e, principalmente de tomada de decisões, assim, durante o primeiro ano de gestão foram realizados estudos no sentido de viabilizar a criação da função de administrador, no quadro de funcionários da entidade.

Segundo o entrevistado, até então, pouco era observado em termos de práticas efetivas de gestão, ou seja, o processo era mais intuitivo do que técnico, causando uma série de entraves e prejudicando o bom funcionamento, principalmente, por ser tratar de uma fundação de apoio ao órgão público, que administra recursos públicos e que por consequência, exige o cumprimento de diversos procedimentos legais. No entanto segundo Tenório (2004) gerenciar é orientar a dinâmica da organização, assim para que uma atividade seja bem sucedida é necessária uma adequada utilização dos recursos, com o direcionamento desses para atingir os objetivos propostos pelos membros da organização.

No início de 2010, foi criada a função de administrador, neste sentido, foram questionados quais seriam as suas atribuições. Segundo Lacombe e Heilborn (2008, p. 3) "a essência do papel do administrador é a obtenção de resultados por meio de terceiros, do desempenho da equipe que ele supervisiona e coordena". O Diretor Executivo respondeu que as principais atribuições seriam: redefinir as ações relacionadas a recursos humanos, desenvolver fluxos de procedimentos internos nos diversos setores, qualificar a relação com os coordenadores de projetos (clientes da Fundação), ajustar a relação com os prestadores de serviços e planejar a atuação da Fundação.

No decorrer dos dois últimos anos, o administrador implantou uma série de ações para atender os objetivos propostos para a função. Em relação, a redefinição das ações com recursos humanos, o entrevistado ressalta, a descentralização das decisões na Diretoria, sendo compartilhada entre o administrador e os funcionários de cada setor, chegando a Diretoria, apenas as decisões mais estratégicas. Desta forma, os funcionários de cada setor, passaram a 


\section{IMPLANTAÇÃO DO PROCESSO DE GESTÃO: ESTUDO DE CASO EM UMA FUNDAÇÃO DE \\ APOIO À UNIVERSIDADE PÚBLICA \\ DOI: http://dx.doi.org/10.5007/1983-4535.2012v5n3p46}

ter poder de decisões em questões operacionais relacionadas à sua função. Conforme a nova administração de Lacome e Heilborn (2008, p. 523), os recursos humanos são fundamentais para a organização, "a empresa deve estar à sua escuta se quiser iniciar o verdadeiro aprendizado de uma administração adaptada ao mundo de hoje".

Outra questão importante destacada pelo entrevistado foi uma redefinição das funções em cada setor, bem como, identificando o reflexo que cada função tem nos demais setores da Fundação. Neste aspecto, é importante notar que, a Fundação, possui um setor de compras, um setor financeiro, um setor de prestação de contas, e mais recentemente foi criado um setor de controle de convênios e contratos, já que essa função de controle era desempenhada inicialmente, pelo administrador.

Também, relacionado a recursos humanos, houve uma significativa mudança nas pessoas, ou seja, substituídos àqueles funcionários que não estavam atendendo o proposto pela redefinição das funções, e houve a necessidade de ampliação no número de funcionário e na quantidade de estagiários. Agregado a isso, foram criados procedimentos de seleção externa e interna, visto que até então a seleção de novos funcionários acontecia por indicação. Foram fixados requisitos mínimos para participação em processo de seleção, bem como, com a realização de processo de seleção interno, foi possível dar oportunidade de crescimento profissional para os funcionários e principalmente para os estagiários que atuavam na entidade.

A criação de novas funções teve reflexo na remuneração, pois foram criados níveis diferentes, de acordo com as atribuições a serem desenvolvidas, visto que até então, todos os funcionários tinham a mesma remuneração.

O Diretor Executivo destaca que a Fundação trata com recursos públicos, assim o setor de compras precisou aprimorar os seus procedimentos, visto que a gestão de recursos públicos exige a utilização frequente de compras via licitação. Conforme Teodósio (1999) o campo de gestão é avaliado como um dos espaços centrais na obtenção do avanço das organizações do terceiro setor, o que exige um esforço no desenvolvimento de instrumentos e estruturas gerenciais apropriados para mensurar e monitorar processos, resultados e impactos em projetos realizados de modo que os objetivos sociais sejam obtidos. Neste sentido, percebeuse a necessidade de um profissional da área de Direito, pois os serviços de assistência jurídica eram terceirizados e eventuais, mas com o crescimento da atuação da Fundação, o setor de compras precisou deste profissional para o acompanhamento das licitações. 


\section{IMPLANTAÇÃO DO PROCESSO DE GESTÃO: ESTUDO DE CASO EM UMA FUNDAÇÃO DE \\ APOIO À UNIVERSIDADE PÚBLICA \\ DOI: http://dx.doi.org/10.5007/1983-4535.2012v5n3p46}

Outra atribuição importante destacada para o Administrador, de acordo com o Diretor Executivo, foi à criação de um manual de procedimentos, pois em função das diversas formas de origens dos recursos de órgãos diferentes, necessitava-se criar procedimentos específicos para cada fonte de recursos; por exemplo, entidades de fomento à pesquisa, exigem procedimentos de compra específicos, já as empresas privadas que contratam serviços da Fundação não se preocupam com a forma de compra realizada. Por isso, dependendo da origem do recurso administrado pela Fundação, a atuação de cada setor será distinta, e por consequência, o fluxo de procedimentos. Neste sentido, o administrador reuniu-se com cada setor, para analisar os procedimentos e criar um documento com a descrição de cada um desses procedimentos, que além de definir o caminho a ser tomado em cada situação, serve como referência cada vez que acontece uma troca de funcionário, diminuindo o tempo de treinamento, visto que a descrição dos fluxos facilita o processo.

Qualificar a relação com os coordenadores de projetos é outro item observado pelo entrevistado, pois o coordenador é o cliente da Fundação, e é ele que apresenta o projeto, para isso precisa de informações sobre todo o funcionamento da Fundação, e quais procedimentos deve seguir. Essa função passou a ser desempenhada pelo administrador, visto que anteriormente, o coordenador dirigia-se a qualquer funcionário, e por muitas vezes recebia informações incompletas. Em contato com o administrador, o coordenador tem uma visão geral sobre como deve proceder e fica sabendo com quem tratar em cada situação específica.

Uma importante preocupação do Diretor era ajustar a relação com os prestadores de serviços, pois a Fundação necessita de serviços, como: contabilidade, auditoria externa, limpeza, manutenção de software, serviços de banda larga, entre outros. A maioria desses serviços, não estava devidamente regulamentado em contratos, bem como, não atendia devidamente ao pretendido, assim, o administrador, renegociou os contratos com os prestadores, principalmente, no sentido de qualificar o serviço relacionado ao software utilizado pela Fundação, visto que o acompanhamento dos recursos disponíveis nos projetos é realizado por esse software, sendo uma importante informação para todos os interessados com o desenvolvimento do projeto. Além disso, foram terceirizados alguns serviços, como, contrato de locação de fotocópias e impressão de cópias, pois se percebeu que o custo de manutenção de máquina de cópias e de cartucho de impressão era mais elevado a locação do equipamento. 


\section{IMPLANTAÇÃO DO PROCESSO DE GESTÃO: ESTUDO DE CASO EM UMA FUNDAÇÃO DE \\ APOIO À UNIVERSIDADE PÚBLICA \\ DOI: http://dx.doi.org/10.5007/1983-4535.2012v5n3p46}

Outro ponto fundamental para o Diretor Executivo foi o planejamento da atuação da Fundação, que até então, era replicar plano de ações do ano anterior, neste ano, foi possível elaborar planejamento para o próximo ano mais adaptado a realidade da entidade, por meio da reunião de um conjunto de informações gerenciais, sobre o que foi desenvolvido na Fundação nos últimos cinco anos e o que se pretende atingir no futuro. De acordo com Teodósio (1999) as funções gerenciais fundamentais ao trabalho do gerente são: planejamento, organização, direção e controle, e essas funções precisam ser entendidas como um ciclo que se repete dentro da organização estando relacionada com previsão, divisão do trabalho, execução e monitoramento. Para Willians (2010), os gestores necessitam se preocupar com a eficiência e eficácia no processo de trabalho, destacando o planejamento sendo este uma das quatro funções administrativas relevante.

Ao final, o entrevistado relatou que a inserção da função do Administrador, e principalmente, o uso do processo de gestão tornou-se um diferencial na atuação da Fundação, pois isso ofereceu mais condições para a Direção tratar das questões estratégicas, sem ter que estar envolvida com as questões operacionais, qualificando assim, o processo administrativo.

\section{CONSIDERAÇÕES FINAIS}

Este estudo teve como objetivo geral identificar quais são as mudanças ocorridas no processo de gestão, a partir de uma nova diretoria em uma Fundação de Apoio à Universidade Pública.

Para tanto, foi descrito quais as ações de gestão adotadas pela nova diretoria na Fundação de Apoio "Alpha" percebeu-se que a Fundação utiliza processo de gestão, pois conforme o Diretor Executivo, as principais ações administrativas utilizadas foram: redefinir as ações relacionadas a Recursos Humanos; criar um manual de procedimentos internos; e, planejar as ações da Fundação até o final do mandato.

Nas ações relacionadas aos recursos humanos, a Fundação de Apoio "Alpha" obteve como a principal contribuição; a descentralização das decisões, sendo compartilhada entre o administrador e os funcionários de cada setor, pois conforme Boudreau e Ziskin (2011) a organização do futuro vai ver todos os funcionários como líderes, e as pessoas vão ter responsabilidade e autoridade para agir ao invés de esperar uma ordem de cima; a criação de novas funções, com reflexo na remuneração, pois foram criados em níveis diferentes, de acordo com as atribuições a serem desenvolvidas; e na realização do processo de seleção 


\section{IMPLANTAÇÃO DO PROCESSO DE GESTÃO: ESTUDO DE CASO EM UMA FUNDAÇÃO DE \\ APOIO À UNIVERSIDADE PÚBLICA \\ DOI: http://dx.doi.org/10.5007/1983-4535.2012v5n3p46}

interna, foi possível dar oportunidade de crescimento profissional para os funcionários, e principalmente, para os estagiários que atuavam na entidade.

Entre as ações de gestão implantadas, o manual de procedimentos interno, trouxe como contribuições: conforme a teoria da burocracia, com suas regras, divisão do trabalho e a hierarquia, o administrador da Fundação passou a reunir-se com cada setor, para analisar os procedimentos e criar um documento com a descrição de cada um desses procedimentos, que além de definir o caminho a ser tomado em cada situação, serve como referência, cada vez que acontece uma troca de funcionário e dependendo da origem do recurso administrado pela Fundação, diferente será a atuação de cada setor, e por consequência, fluxo de procedimentos; outra contribuição foi à qualificação da relação com os coordenadores de projetos, sendo este considerado o cliente da Fundação, com os procedimentos definidos, o coordenador tem uma visão geral sobre como deve proceder e permanece informado com quem deve tratar em cada situação específica; a qualificação do serviço relacionado ao software utilizado pela Fundação. Em relação ao planejamento das ações da Fundação, aparece outro ponto de destaque, as terceirizações de alguns serviços, que contribuíram para que o administrador obtivesse mais tempo para dedicar à atividade principal da Fundação, e traçar seus planos de ação. Para o Diretor Executivo, uma das mais importantes ações foi à criação da função do administrador, e consequentemente, o uso do processo de gestão, que agregaram responsabilidade e compromisso nas ações desenvolvidas pela Fundação.

Observa-se que as organizações pertencentes a este setor são complexas e distintas, alterando na forma de atuação bem como na relação com o Estado e com o mercado, sendo o trabalho voluntário um dos fatores categóricos na existência das organizações do terceiro setor. Este tipo de trabalho é ainda uma realidade pouco visível e valorizada no País, necessitando de muitos incentivos para alcançar o patamar preciso para preencher a demanda social concentrada no País (Soares, 2008).

Conclui-se que as práticas de gestão podem ser aplicadas em organizações de terceiro setor, e que contribuem de forma efetiva para o processo de gestão. As perspectivas para o futuro indicam que o terceiro setor é uma área a ser explorada em outros estudos científicos, como sugestão de pesquisas futuras sugere-se analisar a forma de gestão em outros modelos de instituições do terceiro setor, principalmente no sentido de verificar se a adoção de técnicas de gestão qualifica o seu objetivo de existência, ou seja, apoiar as instituições públicas e cumprir o seu papel social de realizar as ações que o poder público lhe designa. Visto que, 
este estudo foi limitado a uma instituição específica de apoio a uma universidade pública federal.

\section{REFERÊNCIAS}

BOUDREAU, J. W., e ZISKIN, I. The future of $\mathbf{H R}$ and effective organizations.

Organizational Dynamics, n. 4, v. 40, p. 255-266, 2011.

BRANCO, V. S. V. F. Imunidade Tributária e Terceiro Setor: Por maior Transparência e Regulamentação. In: Encontro da ANPAD, 21, Rio de Janeiro. Anais... Rio de Janeiro. CDROM, 1997.

BRASIL. Lei $\mathbf{n}^{\mathbf{0}} \mathbf{8 . 9 5 8}$, de 20 de dezembro de 1994. Dispõe sobre as relações entre as instituições federais de ensino superior e de pesquisa científica e tecnológica e as fundações de apoio e dá outras providências. Brasília, DF. Disponível em:

$<$ http://www.pedagogiaemfoco.pro.br/18958_94.htm> Acesso em 27/12/11.

CERVO, A. L. e BERVIAN, P. A. Metodologia científica. São Paulo: Prentice Hall, 2002.

DAVIES, S. Contracting out employment services to the third and private sectors: A critique. Critical Social Policy, v. 28, n. 2, p. 136-164, 2008.

DAVIS, B. M. Creativity \& Innovation in Business 2010 Teaching the Application of Design Thinking to Business. Procedia - Social and Behavioral Sciences, v. 2, n. 4, p. $6532-$ 6538, 2010.

DEFOURNY, J., e NYSSENS, M. Social enterprise in Europe: At the crossroads of market, public policies and third sector. Policy and Society, v. 29, n. 3, p. 231-242, 2010.

DRUCKER, P. F. Uma era de descontinuidade: orientações para uma sociedade em mudança. 3 ed. Rio de Janeiro: Zahar Editores, 1976.

FERNANDES, R. C. “O que é o Terceiro Setor?”. Em IOSCHPE, E. B. (org.). $3^{\circ}$ setor: desenvolvimento social sustentado. Rio de Janeiro: Paz e Terra, 2005.

GODOY, A. S. Introdução à pesquisa qualitativa e sua possibilidades - uma revisão histórica dos principais autores e obras que refletem esta metodologia de pesquisa em Ciências Sociais. Revista de Administração de Empresas, São Paulo, v. 35, n. 2, p. 57-63, 1995.

HUDSON, M. Administrando organizações do terceiro setor. São Paulo: Makron Books, 1999.

HUDSON, M. Administrando organizações do terceiro setor. Tradução: James F.

Sunderland Cook; revisão técnica: Luiz Carlos Merege. São Paulo: Makron Books, 2002. 
IOSCHPE, E. B. (org.) et al. $3^{\circ}$ setor: desenvolvimento social sustentado. 3 ed. São Paulo: Paz e Terra, 2005.

KOHAMA, H. Contabilidade pública: teoria e prática. 7. ed. São Paulo: Atlas, 2000.

KOONTZ, H. A Miscelânea nas Teorias de Administração. RAE - Revista de Administração de Empresas, v. 6, n. 18, 1966.

LACOMBE, F. J. M., e HEILBORN, G. L. J. Administração: princípios e tendências. 2 ed. São Paulo: Saraiva, 2008.

LINDENMEIER, J., SCHLEER, C., e PRICL, D. Consumer outrage: Emotional reactions to unethical corporate behavior. Journal of Business Research, In Press, Corrected Proof, 2011.

MARTINS, G. A., e THEÓPHILO, C. R. Metodologia da Investigação Científica para Ciências Sociais Aplicadas. 2 ed. São Paulo: Atlas, 2009.

MAXIMIANO, A. C. A. Introdução à administração. 7 ed. São Paulo: Atlas, 2007.

MOTTA, F. C. P., e VASCONCELOS, I. G. de. Teoria Geral da Administração. 3 ed. São Paulo: Cengage Learning, 2008.

PAES, J. E. S. Fundações e Entidades de Interesse Social: aspectos jurídicos, administrativos, contábeis e tributários. 3 ed. Brasília: Brasília Jurídica, 2001.

PHILLIPS, S., e HEBB, T. Financing the third sector: Introduction. Policy and Society, v. 29, n. 3, p. 181-187, 2010.

RESENDE, T. de A. (2006). Roteiro do Terceiro Setor. Associações e Fundações: o que são, como instituir, administrar e prestar contas. 3 ed. Belo Horizonte: Prax, 2006.

SILVA, R. O. Teorias da Administração. São Paulo: Pioneira Thomson Learning, 2005. SOARES, A. C. A. A. (2008). Desafios gerenciais de organizações do terceiro setor de Belo Horizonte na percepção de seus gerentes. Dissertação (Mestrado em Administração) Faculdade Novos Horizontes, Belo Horizonte, 2008.

SZAZI, E. Terceiro Setor: Regulação no Brasil. 4 ed. São Paulo: Petrópolis, 2006.

TENÓRIO, F. G. Gestão de ONGs: principais funções gerenciais. 8 ed. Rio de Janeiro: Fundação Getúlio Vargas, 2004.

TEODÓSIO, A. S. S., e RESENDE, G. A. Desvendando o terceiro e setor: trabalho e gestão em organizações não governamentais. In: Congresso Latino-Americano de Estratégia da Sociedade Latino-Americana de Estratégia, Porto Rico, Lima: CLADEA, CD-ROM, 1999. 
TRISTÃO, G. O papel das fundações na modernização das universidades federais. In: V Congresso Internacional del CLAD sobre la Reforma Del Estado y de la Administración Pública, Santo Domingo, Rep. Dominicana, 24-27, 2000.

YIN, R. K. Estudo de caso: planejamento e métodos. 3 ed. Porto Alegre: Bookman, 2005.

WILliANS, C. Administração. Tradução Roberto Galman. São Paulo: Cengage Learning, 2010 . 